\title{
Ciudad contemporánea y presencia de la Iglesia
}

\author{
Contemporary cities and the presence of the church
}

Claudia Manenti

https://doi.org/10.17979/aarc.2011.2.2.5067

La ciudad contemporánea europea se muestra como compuesta por dos partes distintas y profundamente diversas en las características compositivas y de significado: el centro histórico, con un tejido sedimentado a lo largo de los siglos, habitualmente de modestas dimensiones y todavía reconocible en sus antiguos límites; y la periferia, que en poco más de un siglo ha alcanzado dimensiones muy superiores a toda la superficie del núcleo antiguo. Las dos partes difieren entre sí en lo que respecta a la estructura de la trama urbana, ya sea por la diferente cualidad de los lugares de socialización, o ya, de forma concreta, en cuanto se refiere a la prestancia y presencia de lo sacro.

Para captar las razones y los elementos capitales de la ciudad contemporánea, a fin de evaluar cuáles desempeñan en ella el posible papel de lugar cultual, es preciso recorrer las etapas fundamentales del desarrollo de la ciudad e intentar comprender las razones de peso en relación con lo sacro.

Que la ciudad se haya expresado como realidad sacra desde sus comienzos es un dato de hecho, así como se ha establecido definitivamente que desde sus primeras manifestaciones el asentamiento humano estable hace referencia explícita a un sistema cosmogónico capaz de conferir orden y estabilidad al habitar sobre la tierra ${ }^{1}$.

El ejemplo de Uruk y de las primeras ciudades de Oriente Medio, evidencia la absoluta preeminencia del templo como base generadora de todas las relaciones sociales dentro de lo urbano ${ }^{2}$, mientras que el plano de la planta de la ciudad romana, estrechamente ceñido al modelo del Templum celeste ${ }^{3}$, sitúa a la construcción urbana en el centro de un proyecto creativo que tiene como base el replanteamiento del modelo cósmico.

La ciudad se manifiesta, en efecto, como realidad sacra, con las características propias de la centralidad, y se estructura a partir de una manifestación de la trascendencia que determina el carácter y el lugar. En la concepción arcaica y primitiva, el Centro es considerado como el lugar donde la comunicación vertical entre el cielo, la tierra y el infierno es posible, como punto de intersección de la tierra con el Axis Mundi, el eje cósmico en torno al cual se ha creado el universo.

En el interior de la ciudad histórica, los templos, como lugares destinados exclusivamente al encuentro con lo sacro, tanto como lugares mayormente significativos para la vida de la comunidad, son considerados como centralidades capaces de conferir orientación, significado y sentido de pertenencia ${ }^{4}$.

A pesar de las diferencias fundamentales entre la concepción del templo precristiano como lugar de la manifestación hierofánica de la divinidad, y la realidad del edificio eclesial como lugar de asamblea donde el pueblo de Dios se reúne para celebrar la Eucaristía - es decir, el Cuerpo de Cristo entendido como único y verdadero templo- - se puede sostener que en la ciudad europea, desde el Medioevo hasta el siglo XIX, la iglesia ha 


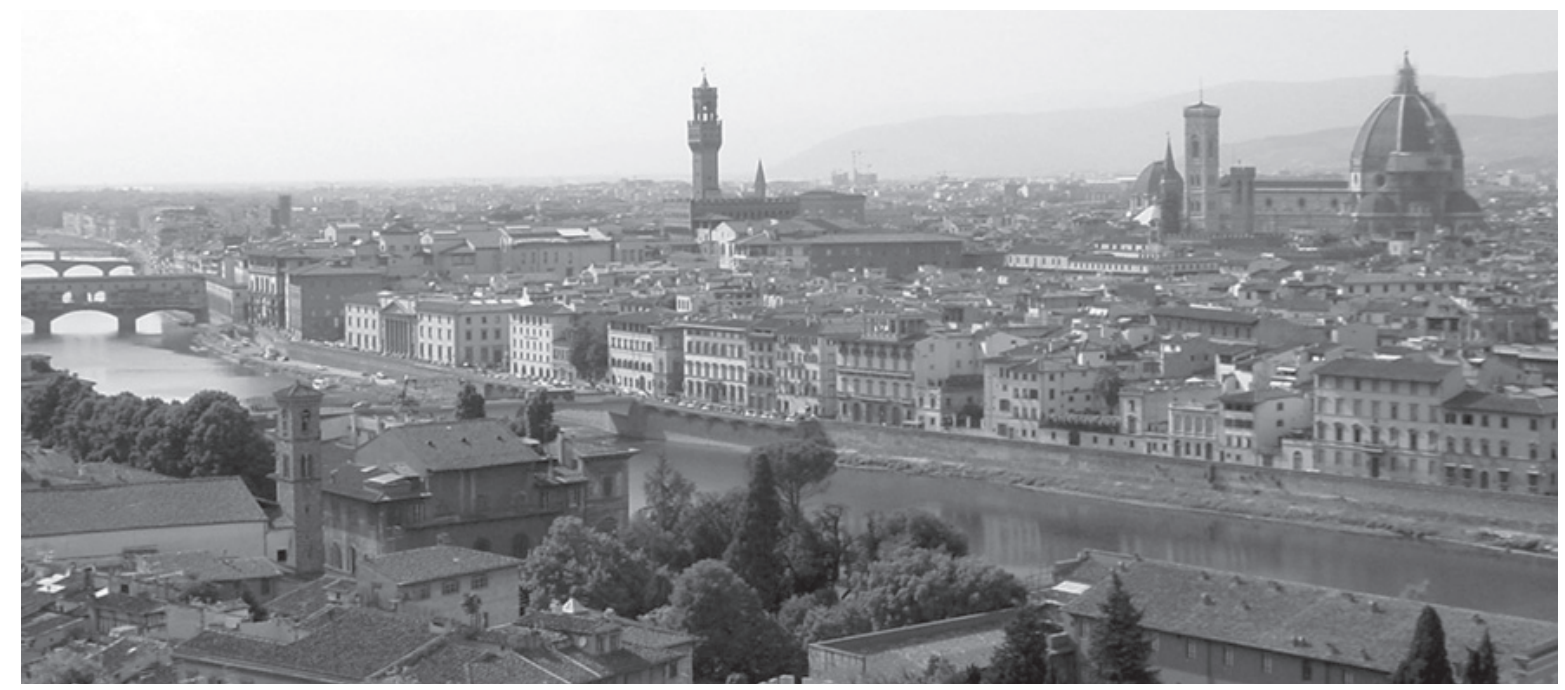

Fig. 1. Duomo y palazzo della Signoria, Florencia.

sido entendida como una centralidad física y significativa con referencia a la realidad existencial (Fig. 1).

En efecto, en el núcleo antiguo de la ciudad europea, la presencia de la catedral y del palacio constituyen las dos centralidades representativas de la vida comunitaria, y estructuran el espacio urbano a través de una estrecha relación entre centralidad y recorridos que permite la percepción de una imagen urbana clara y fácilmente reconocible, tanto en sus aspectos espaciales, como en los simbólicos 5 .

A partir de las ideas propuestas en la Era de las Luces, la claridad de las relaciones entre el tejido secundario de la ciudad y la centralidad entra en crisis, y en cambio, deja lugar a propuestas arquitectónicas y urbanísticas que retratan una concepción del mundo y de la vida humana carente de toda ligazón entre cielo y tierra.

En la actividad teórica y arquitectónica de ClaudeNicolas Ledoux 6 , sobre todo, se puede localizar una transposición en términos espaciales de la teoría filosófica del deísmo que, excluyendo toda posibilidad de ligazón entre lo humano y lo divino, hace de hecho imposible la elección de centralidades como lugares de referencia respecto a la trascendencia. De esta manera, queda conceptualmente abolida la posibilidad de una estructura espacial significativa en cuanto a su capacidad para poner en comunicación «el cielo y la tierra, lo humano y lo divino» ${ }^{7} \mathrm{y}$, por tanto, según la conocida definición de Heidegger, para permitir al hombre habitar sobre la tierra.
Considerada como imposible cualquier relación con la divinidad, la iglesia o el templo llegan a ser esencialmente inútiles; los edificios elegidos para el ejercicio del poder político ya no son reconocidos como representativos de la vida comunitaria, y todos los edificios construidos se declaran igualmente importantes y similarmente representativos ${ }^{8}$. La pérdida de representatividad social se traduce, así, en la exaltación de la unicidad de cada edificio y en la magnificación de la función como única posibilidad de diferenciación arquitectónica.

En los planes y en las teorías urbanísticas propuestas a partir de mediados del siglo XIX, se pueden evaluar los efectos de las ideas maduradas en el seno de la Ilustración, que se traducen en una preeminencia del factor funcional sobre el simbólico, en la abolición de toda arquitectura ideada como representativa, en el aislamiento de los edificios respecto de los demás y del entorno, en la caracterización individualista de toda construcción, y en la indiferencia hacia el proceso histórico y las características del lugar, así como en la ausencia casi total de edificios cultuales. Se asiste en este momento al nacimiento, en el interior de la ciudad, de nuevas centralidades más débiles y efímeras que las precedentes - como el parque de estilo inglés, el museo, las exposiciones (Fig. 2) o la fábrica-, a los que se añade o sustituye hoy en día el centro comercial (Fig. 3), el centro de negocios y el parque de atracciones 9 . 


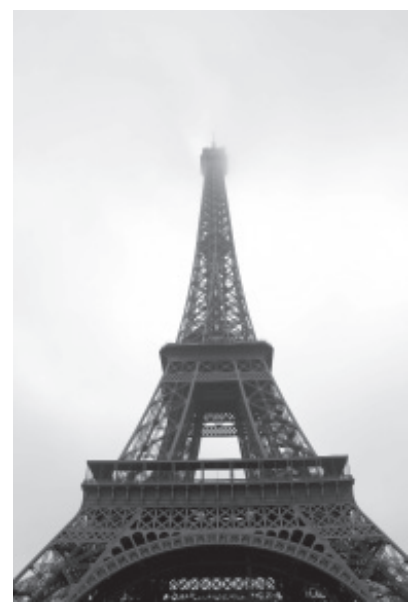

Fig. 2. Torre Eiffel, París.



Fig. 3. Centro Comercial Meridiana, Casalecchio di Reno.
Considerando con Francoise Choay, que «en el origen de cada propuesta de ordenación, detrás de las racionalizaciones o del saber que pretenden hacerla pasar por verdad, se ocultan tendencias y sistemas de valores» ${ }^{10}$, resulta evidente cómo cada nueva centralidad que se propone para la ciudad manifiesta y expresa, de manera más o menos consciente, un sistema de valores de referencia.

A título de ejemplo, se puede comprobar cómo ya en el Plan de ampliación de la ciudad de Bolonia de 1889, así como en muchos otros planes contemporáneos, se ha establecido la propuesta de un crecimiento urbano basado en el factor funcional de la red de viales y en las posibilidades del alquiler, sin ninguna previsión de espacios de socialización civil o cultual ${ }^{11}$ (Fig. 4).

Entrando en el fondo del tema de la presencia del lugar litúrgico católico en la ciudad contemporánea, es necesario preguntarse: ¿cuál es el papel actual, espacial y social, de la iglesia y de cualquier otro espacio cultual respecto a lo urbano?

Visto el declinar del concepto de diferenciación y de representatividad de los edificios respecto a la vida públi$\mathrm{ca}$, es prioritariamente necesario volver a reconocer el papel del edificio público en la ciudad, en cuanto que la atribución de una justa representatividad a dichas construcciones es una premisa indispensable para que también los edificios eclesiales encuentren su lugar propio en la vida social de la ciudad.
Según Cristian Norberg-Schulz, el edificio público es el espacio en el cual tiene lugar el acuerdo entre personas alrededor de intereses comunes o valores genéricos, y en este tener lugar están situadas las bases para la construcción y la existencia de la comunidad y de la sociedad. En efecto, es propio del edificio público el cometido de proponer un conjunto de valores o ideas, y de ser, en sus formas físicas «la explicación visible de un mundo común» 12 .

El edificio público debe, por lo tanto, constituir una centralidad de referencia en el panorama urbano: el ayuntamiento debe hablar de la organización de la sociedad, la escuela de la formación de los jóvenes miembros de la comunidad, el museo de la custodia de la memoria colectiva. La iglesia, en cambio, como todo lugar de culto, debe abrazar los significados existenciales más amplios, mostrando una concepción general del mundo y de la vida. Efectivamente, la iglesia como lugar, debe encarnar «la propiedad fundamental del mundo de la creación. Mientras que todos los demás edificios manifiestan mundos parciales, la iglesia tiende al general. Debería mostrar a menudo la esencialidad de la relación entre la tierra y el cielo» ${ }^{13}$.

$\mathrm{Al}$ intentar un análisis del papel real de la iglesia en la ciudad contemporánea, es particularmente interesante verificar el papel de lo sacro en la construcción de aquellos entornos poblacionales de reciente formación, donde la identidad urbana no puede recurrir a formas consolidadas del pasado y necesita una laboriosa toma de 


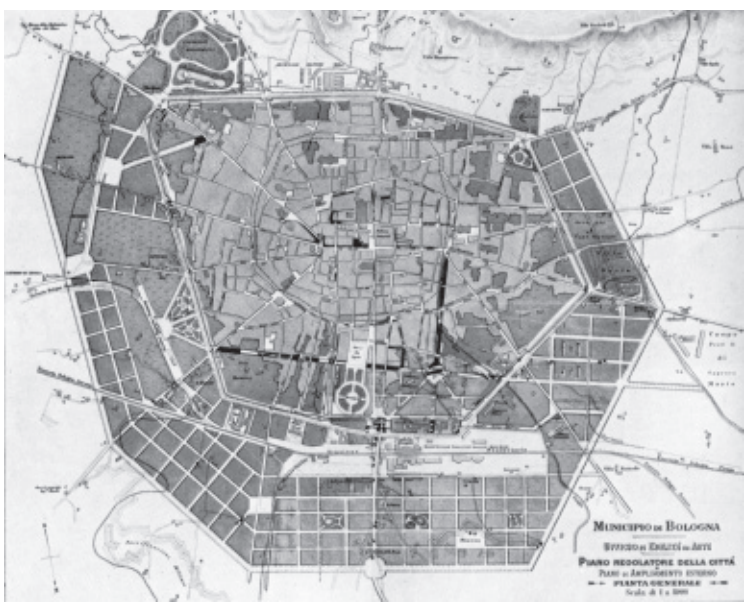

Fig. 4. Plan de Regulador de la ciudad de Bolonia, 1889.

Plan de Ampliación Exterior. Planta general.

conciencia por parte de las administraciones para identificar cuáles son los elementos capaces de determinar el significado y la orientación dentro de una ciudad, y qué es capaz de generar identidad y espíritu de pertenencia en los nuevos habitantes.

El ejemplo de las villes nouvelles de las conurbaciones parisina y lionesa es particularmente elocuente en este sentido, en cuanto que estas nuevas organizaciones urbanas se han creado en el periodo 1960/75 con una voluntad de dar una exacta interpretación de los principios urbanísticos del Movimiento Moderno, entre los cuales no figuran las necesidades de tipo cultual.

En absoluta aceptación de los principios de la Carta de Atenas, los proyectos iniciales de estas nuevas ciudades de nueva fundación están, por tanto, caracterizados por la separación de las funciones y de los flujos de tráfico, por la presencia de amplias zonas verdes y por los edificios residenciales distanciados entre sí y dispuestos en vertical, y a menudo colocan en el centro del sistema urbano la caja del centro comercial, conectado con el sector dedicado a la cultura y la administración.

Si en la realización de los proyectos de nuevas ciudades se verifica una presencia de lugares de culto absolutamente marginal, insertados y casi siempre diluidos dentro del conjunto residencial, es interesante destacar, en cambio, cómo en las primeras redacciones de los proyectos se previeron a menudo los centros de espiritualidad, situados en posición dominante respecto al conjunto urbano (Fig. 5).

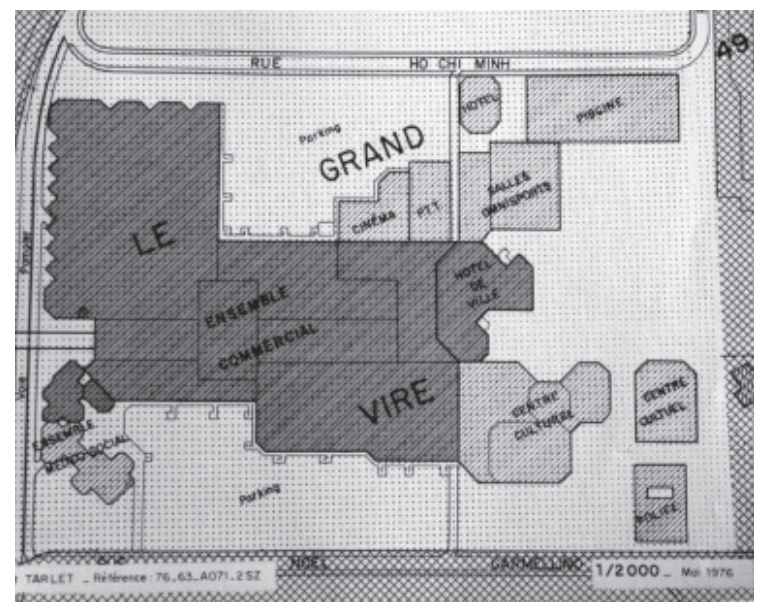

Fig. 5. Vaux la Grande lle. Diseño de Sectores.

Sociedad de Equipamiento de la Región de Lyón. Vaulx-en-Velin. Zona a urbanizar con prioridad, 1976.

La fallida realización de dichas previsiones proyectuales no ha sido, por norma, consecuencia de una elección administrativa, sino que es debida a la voluntad eclesiástica de interpretar la espiritualidad de la ocultación, propia del periodo posterior al sesenta y ocho, a través de una modalidad de presencia en el contexto urbano discreta, humilde y oculta, contra todo triunfalismo y estímulo de ostentación. Así, se observa que los edificios litúrgicos de estos años son a menudo poco reconocibles, privados de toda referencia simbólica, e interpretando la imagen de la iglesia como casa entre casas, imagen querida por el deseo de un retorno a la modalidad de presencia de los cristianos en el mundo propia de los primeros siglos (Fig. 6).

Sin embargo, ya desde fines de los años ochenta, dentro de la Iglesia francesa se hace hueco una interesante reflexión acerca del hecho de que dicha presencia oculta de la comunidad cristiana no ha dado los resultados esperados, y en cambio, ha privado a la ciudad de puntos de referencia estables y significativos, capaces de ser un reclamo y un apoyo en la vida cotidiana. Como consecuencia de dichas reflexiones se ha puesto en marcha un proceso operativo, todavía en curso, tendente a hacer nuevamente visibles y significativos a los lugares de culto católico; en Crèteil, a $8 \mathrm{~km}$. de París, el obispo ha expresado recientemente el deseo de una modificación estructural de la catedral de Notre-Dame de Crèteil, construida el los años setenta con formas particularmente modestas y funcionales, con la intención de ampliar la 


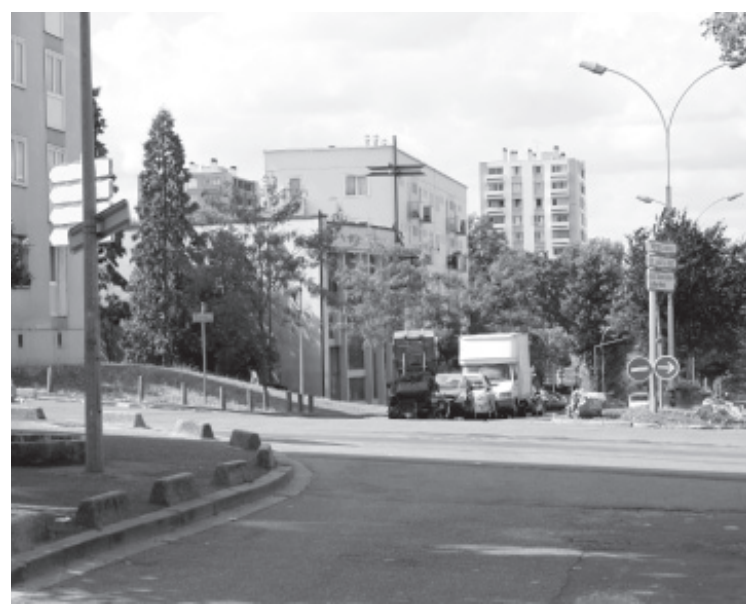

Fig. 6. Iglesia de St. Michel a Mont-Mesly, Crèteil.

capacidad de la nave litúrgica, pero también de aumentar en altura el volumen y proponer a la ciudad un nuevo hito urbano, de tipo campanario, capaz de hacer mayormente visible e identificable el lugar cultual (Fig. 7).

En Evry, a unos $30 \mathrm{~km}$. de París, la cuestión de la necesidad de la presencia del edificio eclesial en la estructuración identitaria de la ciudad se ha sentido especialmente, en todo lo típico de las vicisitudes de esta ville nouvelle, y ha abierto el debate sobre la necesidad de una manifestación también exterior de la presencia de la Iglesia en la ciudad.

Ya en la época del primer proyecto constitutivo de Evry, el obispo local había sido interpelado por la administración para estudiar la posibilidad de crear un centro cultual en el centro de la ciudad; el prelado, que en un primer momento, desde la óptica de una iglesia no visible, había propuesto una presencia eclesial difuminada en pequeñas naves, hacia finales de los años ochenta llega al convencimiento de la irrenunciable necesidad de la población ciudadana y de los numerosos habitantes nuevos, de tener un edificio eclesial visible y reconocible, como punto de referencia orientativa estable, claro y legible en el interior del conjunto urbano ${ }^{14}$.

La Catedral de Evry, construida por el arquitecto Mario Botta, se levanta hoy como seguro punto de referencia, y ha entrado con todo derecho a formar parte de la imagen identitaria de la ciudad; con su maciza presencia ubicada al lado de los edificios del Ayuntamiento, de la

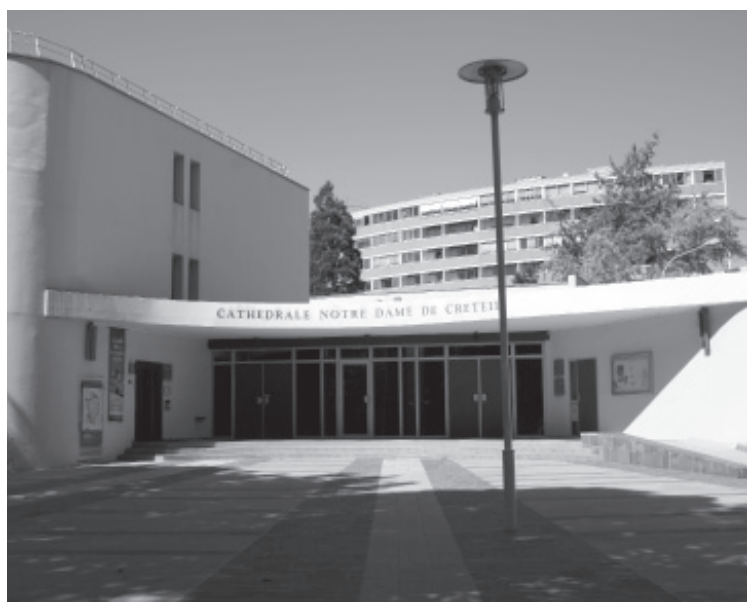

Fig. 7. Catedral de Notre-Dame, Crèteil.

Cámara de Comercio y del Conservatorio de Música, participa de modo significativo en la construcción de un espacio de gran valor urbano (Fig. 8-10).

Es interesante comprobar cómo en un país como Francia, único en el respeto al principio de laicidad, la Iglesia local está a menudo involucrada en las reflexiones urbanísticas propuestas por la administración; lo que se le reconoce a la comunidad cristiana es la capacidad de crear espacios de conexión con una tradición cultural particularmente importante en contextos de multiculturalidad y de multiplicidad de religiones, de saber proponer una búsqueda artística y una reflexión cultural abierta a la ciudad, y de ser un punto de referencia para una acción eficaz de integración social en entornos sensibles y de fuerte inmigración.

Concluyendo, creo que es de una importancia fundamental en el diseño del edificio eclesial una clara toma de conciencia del papel social y urbano ejercido por el lugar de culto cristiano. Hay necesidad de una nueva consideración hacia la localización y la forma arquitectónica de la iglesia. En cuanto que representativo del vínculo entre el cielo y la tierra, el edificio eclesial en la ciudad no puede sino constituir una centralidad y estar señalado por alguna verticalidad, sin caer en triunfalismos nostálgicos, pero también sin el temor de manifestar la dignidad de una voluntad de relación con los hombres y con Dios.

La iglesia, como todos los espacios de culto, no es una presencia importante solo para el que se declara 


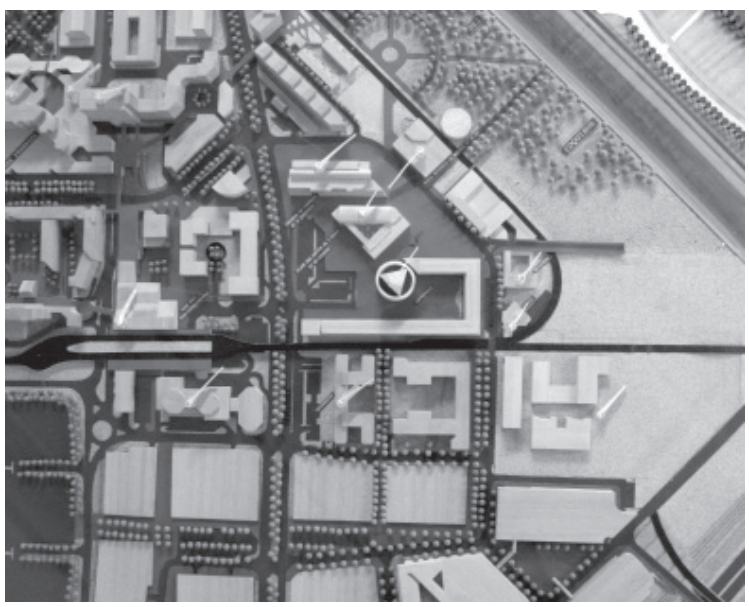

Fig. 8. Maqueta de la zona central de Evry.

cristiano, sino que constituye un punto de orientación central y de significados que la ciudad necesita; con su apariencia física tiene la tarea de interpelar la conciencia de los hombres y las mujeres de nuestro tiempo sobre el significado último de la existencia humana, y la de proponer serenamente la posibilidad de una relación estructurada entre la realidad terrena y el misterio ultraterreno asumiendo, de este modo, el papel universal que le es propio.

\section{NOTAS}

(1) Cf. Lewis Mumford, «La cittá nella storia», Edizioni di Comunitá, Turin, 1963, pag. 49; Mircea Eliade, «Il mito dell'eterno ritorno», Rusconi, Milan, 1975; pág. 26.

(2 Paolo Xella, «La cittá divina: cultura urbana e politeísmo nel Vicino Oriente», en Franco Cardini (ed.), «La cittá e il Sacro», Garzanti Scheiwilleer, Milan, 1994; pág. 12.

(3) Joseph Rykwert, «L’idea di cittá», Adelphi, Milan, 2002; pág. 39.

(4) Cf. Mircea Eliade, «Il mito dell'eterno ritorno», cit.

(5) Cf. Christian Norgberg-Schulz, «Genius Loci» Electa, Milan, 1979.

(6) Cf. Claude-Nicolas Ledoux, «L'architecture», Herman, Paris, 1997.

(7) Martin Heidegger, «Saggi e discorsi», Mursia, Milan, 1998; pág. 99.

(8) Emil Kaufmann, «Da Ledoux a Le Corbusier. Origini e sviluppo dell'architettura autonoma», Mazzotta, Milan, 1973; pag. 94.

(9) Hans Seldmayr, «Perdita del centro», Borla, Roma, 1983; pág. 21.

(10) Françoise Choay, «La cittá. Utopie e realtá», Einaudi, Turin, 2000; pág. 72 .

(11) Cf. Carlo Cesari y Giuliano Gresleri, «Residenza operaia e cittá neo-conservatrice. Bologna caso esemplare», Officina Edizioni, Roma, 1976.

(12) Christian Norgberg-Schulz, «L’abitare», Electa, Milan, 1984; pág. 13.

(13) Loc. cit.

(14) Cf. Jacques Guyard, «Evry, ville nouvelle 1960-2003», Espace Sud, Evry, 2003.

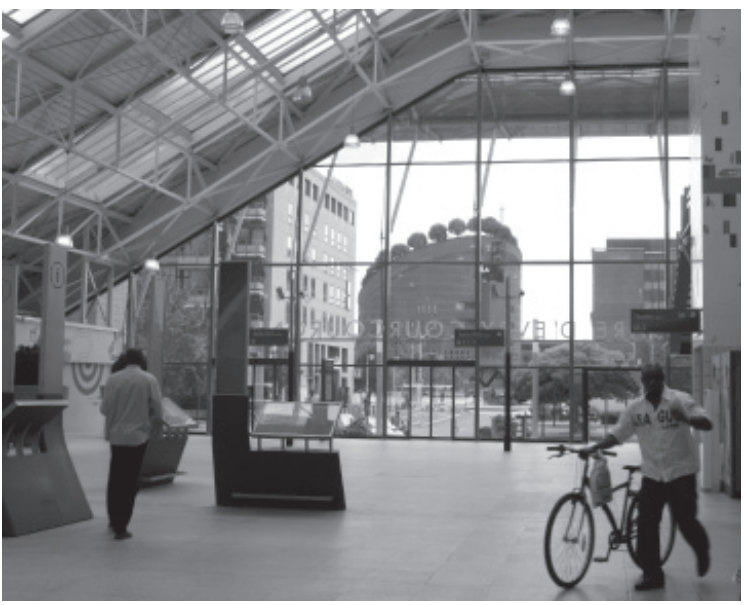

Fig. 9. Catedral de la Resurrección, Evry. Vista desde la estación.

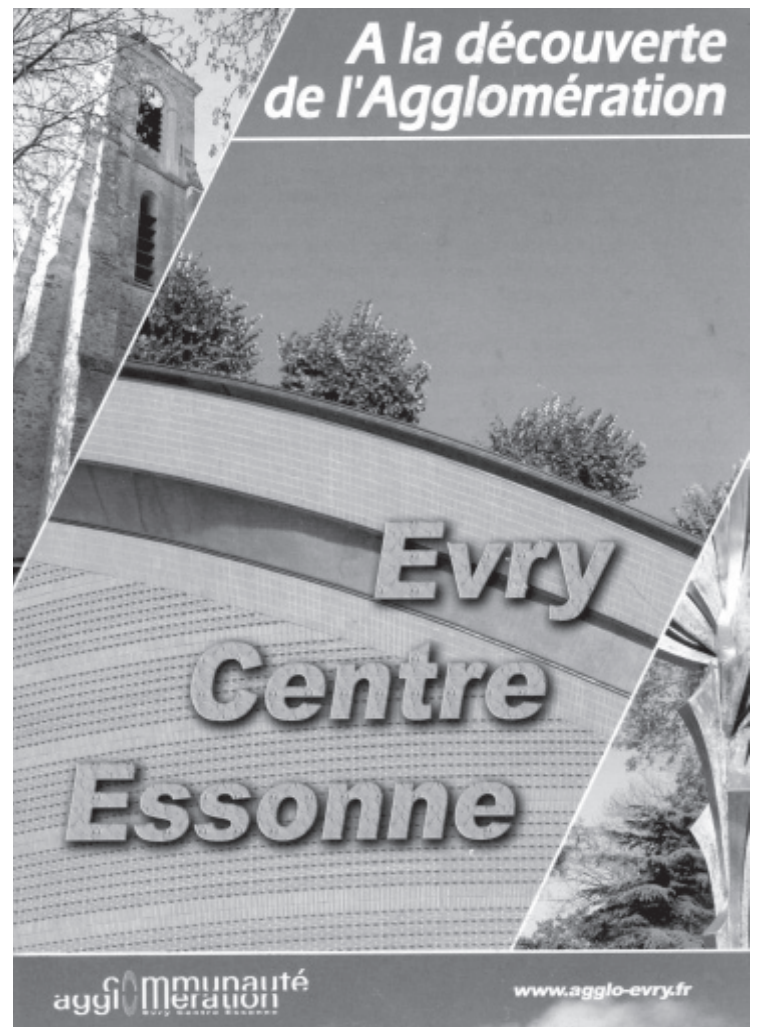

Fig. 10. Portada del folleto de presentación de la aglomeración urbana Evry-Centre Essonne. 